NBER WORKING PAPER SERIES

\title{
ESTIMATING THE VALUE OF A STATISTICAL LIFE: \\ THE IMPORTANCE OF OMITTED VARIABLES AND PUBLICATION BIAS
}

\author{
Orley Ashenfelter \\ Michael Greenstone \\ Working Paper 10401 \\ http://www.nber.org/papers/w10401 \\ NATIONAL BUREAU OF ECONOMIC RESEARCH \\ 1050 Massachusetts Avenue \\ Cambridge, MA 02138 \\ March 2004
}

The views expressed herein are those of the author(s) and not necessarily those of the National Bureau of Economic Research.

(C)2004 by Orley Ashenfelter and Michael Greenstone. All rights reserved. Short sections of text, not to exceed two paragraphs, may be quoted without explicit permission provided that full credit, including (C) notice, is given to the source. 
Estimating the Value of a Statistical Life:

The Importance of Omitted Variables and Publication Bias

Orley Ashenfelter and Michael Greenstone

NBER Working Paper No. 10401

March 2004

JEL No. J17, H43, I18, R4

\section{$\underline{\text { ABSTRACT }}$}

In this paper we show that omitted variables and publication bias lead to severely biased estimates of the value of a statistical life. Although our empirical results are obtained in the context of a study of choices about road safety, we suspect that the same issues plague the estimation of monetary trade-offs regarding safety in other contexts.

Orley Ashenfelter

Industrial Relations Section

Firestone Library

Princeton University

Princeton, NJ 08544

and NBER

c6789@princeton.edu

Michael Greenstone

MIT, Department of Economics

50 Memorial Drive, E52-391B

Cambridge, MA 02142-1347

and NBER

mgreenst@mit.edu 


\section{ESTIMATING THE VALUE OF A STATISTICAL LIFE: THE IMPORTANCE OF OMITTED VARIABLES AND PUBLICATION BIAS}

\section{By ORLEY ASHENFELTER AND MICHAEL GREENSTONE*}

Measures of public preferences toward risk are critical to evaluations of public policies on many safety, environmental, and health issues. In this paper we provide a method for measuring the revealed preferences for safety risks from state level public choices about speed limits. The idea is to measure the value of the time saved per incremental fatality that results from the voluntary adoption of an increased speed limit. Since adopters must have valued the time saved by greater speeds more than the fatalities created, this ratio provides a convincing and credible upper bound on the value of a statistical life (VSL). ${ }^{1}$

Although there have been a number of creative attempts designed to estimate the value of a statistical life, there have been few opportunities to obtain estimates based on the public's willingness to accept an exogenous and known safety risk and to do this for multiple independent decision makers. ${ }^{2}$ The empirical analysis we report here exploits the opportunity that the federal government gave the states in 1987 to choose a speed limit for rural interstate highways that was higher than the uniform national maximum speed limit then in existence.

This institutional change allows us to address two key conceptual problems that have plagued previous attempts to estimate the VSL. First, most methods for assessing the VSL from labor market data are not based on choices made in the face of exogenous safety risks. This results in estimates of the VSL that often are not based on credible identification assumptions or suffer from serious potential omitted variables bias. ${ }^{3}$ For example, we demonstrate that conventional ordinary least squares (OLS) estimation indicates that speeds and highway fatality rates are uncorrelated, presumably due to drivers' optimizing decisions. To avoid this problem of omitted variables, we use states' decisions about adopting a higher speed limit in response to the 1987 law as an instrumental variable (IV). In sharp contrast to the OLS results, this IV estimation strategy indicates that speeds and fatalities are highly correlated and that adopters received approximately \$1.5 million (1997\$) per marginal fatality.

Second, our estimates of the tradeoff between the value of time saved and fatalities can be made from comparisons of rural interstates and other highways within states that adopted increased speeds, as 
well as from comparisons with roads in non-adopting states. This statistical design permits us to obtain separate estimates of this tradeoff for each of the states with complete data that changed speed limits. Consequently, we can also examine how "publication bias" might lead to "consensus" estimates of the VSL being determined by a selected sample of the estimated tradeoffs. Since only "successful" analyses are likely to be published, we implement several of the most likely "publication rules" and show that the consensus estimate is likely to be significantly upward biased by publication bias. ${ }^{4}$

\section{Design of the Study}

The first U.S. laws imposing restrictive speed limits on motor vehicles were passed in 1901 in Connecticut. With the exception of a Second World War emergency limit of $35 \mathrm{mph}$, the setting of speed limits remained the responsibility of the state and local governments until 1974 when Congress enacted the Emergency Highway Energy Conservation Act. This bill, intended as a fuel conservation measure, required, among other things, a national maximum speed limit of $55 \mathrm{mph}$. This new national speed limit was lower than the existing maximum daytime speed limit in all 50 states.

The Federal Highway Administration was empowered to enforce the new speed limit by the use of financial sanctions. By 1987 dissatisfaction with the federally imposed (and enforced) national maximum speed limit led Congress to modify the law to permit states to set speed limits of 65 mph on rural interstate highways only. Forty states immediately exercised this option. Even with the end of the concern for fuel conservation, the national maximum speed limit was retained in some form until repeal in 1995. By the end of 1997 only three states maintained a 55 mph speed limit on rural interstates: 20 states had rural interstate speed limits of $65 \mathrm{mph}, 16$ were at $70 \mathrm{mph}, 10$ at $75 \mathrm{mph}$, and Montana had no daytime speed limit, returning to its policy in 1973.

In this paper we study 21 of the 40 states that chose to raise their speed limits to 65 miles per hour on rural interstate highways by 1988. The remaining states had no rural interstate highways (3), did not change their speed limit (7), or were states for which we could not obtain reliable data (19). Uniform and reliable data on the post-1995 period is unavailable at this time, but we hope to extend our analysis to this period when possible. 
Our operating hypothesis is that the legislative decisions about speed limits can be used to infer the VSL of an individual whose preferences are important for maximizing societal welfare. This requires that: (a) lawmakers were aware of the tradeoffs associated with a higher speed limit; and, (b) the legislators' adoption decisions reflect the preferences of a driver/voter toward the center of the distribution of preferences

We find both of these assumptions plausible. First, there was considerable evidence available to legislators in 1987 on the effects of higher speed limits on average speeds and fatality rates. Importantly, this evidence was collected and summarized in a widely disseminated report by the National Research Council (NRC 1984). Second, there is ample anecdotal evidence that in choosing a speed limit states aim to maximize societal welfare. For example, an Indiana Department of Transportation report states: "Speed limits represent trade-offs between risk and travel time for a road class or specific highway section reflecting an appropriate balance between the societal goals of safety and mobility. The process of setting speed limits is not merely a technical exercise. It involves value judgments and trade-offs that are in the arena of the political process" [italics added] (Khan, Sinha, and McCarthy, 2000, p. 144).

Further, one might expect that if the 1987 adoption decisions were in conflict with driver/voter preferences that states would reverse their decisions over time. Notably, none of the states exercised this option.

\section{What is Being Measured?}

Assuming that decisions to increase speed limits reflect informed voter preferences, there still remains the question of what part of the distribution of preferences is measured by our empirical analysis. To study this problem, it is essential to distinguish between (a) the technical constraint that connects speeds to fatalities and (b) the preferences of voters as between speed and fatality risks. We may observe the technical constraint, but we can only infer voter/driver preferences from their choices.

To understand the issues, suppose the median driver/voter in state i is offered the opportunity to

increase the speed limit from $\bar{S}_{i}$ to $\bar{S}_{i}$ ' through the political process. Associated with this offer is a decrease in the cost of travel time of $\mathrm{w} \Delta \mathrm{h}_{\mathrm{i}}$, which is measured as the product of the value of time ( $\mathrm{w}$, the 
wage) and the amount of time saved (measured in hours, h). Also associated with this offer is an increase in the fatality rate (f) of $\Delta \mathrm{f}_{\mathrm{i}}$, so that we may display the heterogeneity in this offer by writing

$$
\mathrm{V}_{\mathrm{i}}=-\mathrm{w}\left(\Delta \mathrm{h}_{\mathrm{i}} / \Delta \mathrm{f}_{\mathrm{i}}\right)
$$

The left hand side of equation (1) is a discrete measure of the value of time saved (V) as a result of the speed limit change. We use the 1987 law to estimate the $\mathrm{V}_{\mathrm{i}}$ 's, as well as their mean.

The value of a statistical life, $\mathrm{V}_{\mathrm{i}}{ }^{*}$, reflects the preferences toward safety (the rate of substitution between money and risk) of the determining driver/voter in state i. ${ }^{5}$ A higher speed limit will be adopted if $\mathrm{V}_{\mathrm{i}}>\mathrm{V}_{\mathrm{i}}{ }^{*}$, for in this case the time costs saved by the increased speeds that result from the higher speed limit will be greater per fatality than the value of the determining statistical life, $\mathrm{V}_{\mathrm{i}}{ }^{*}$. The probability that the higher speed limit is adopted is thus:

$$
\operatorname{Pr}(\text { Adoption })=\operatorname{Pr}\left(\mathrm{V}_{\mathrm{i}}>\mathrm{V}_{\mathrm{i}}{ }^{*}\right) \text {. }
$$

It is apparent from (2) that the average value of $\mathrm{V}_{\mathrm{i}}$ amongst adopters, $\mathrm{E}\left(\mathrm{V}_{\mathrm{i}} \mid\right.$ Adoption $)=$ $\mathrm{E}\left(\mathrm{V}_{\mathrm{i}} \mid \mathrm{V}_{\mathrm{i}}>\mathrm{V}_{\mathrm{i}}{ }^{*}\right)$, must be at least as great as $\mathrm{E}\left(\mathrm{V}_{\mathrm{i}}{ }^{*} \mid\right.$ Adoption), the average value of a statistical life among adopters. Thus, the measured average value of time costs saved per marginal fatality from the adoption of an increased speed limit is generally greater than the mean value of a statistical life among adopters and provides an upper bound on that quantity. In addition in the special case where the value of a statistical life is constant across states (i.e., $\mathrm{V}_{\mathrm{i}}{ }^{*}=\mathrm{V}^{*}$ ), the estimated average value of the time saved per marginal fatality from an increased speed limit is upward biased compared to what it would be for both adopters and non-adopters because the left hand side of equation (1) is only observed for adopters. ${ }^{6}$

\section{Data and Econometric Methods}

Data Sources. To conduct the analysis, we collected a data file on vehicle miles traveled (VMT), traffic fatalities, and vehicle speeds that covers the years 1982-1993 for urban and rural interstate highways and for rural arterial roads. States were allowed to increase the speed limit to $65 \mathrm{mph}$ on rural interstates. They were prohibited from increasing the limit on the other two. Since these other roads generally had speed limits of $55 \mathrm{mph}$ in 1987 and design features that closely resemble those of rural interstates, these two road types provide an important source of intra-state variation. ${ }^{7}$ 
VMT is readily available by state and road type from the Federal Highway Administration's Highway Statistics. ${ }^{8}$ Total fatalities by road type are available from the Fatal Accident Reporting System, which provides a census of all fatal vehicle crashes in the United States. By contacting all state departments of transportation, we obtained speed data for 21 of the 40 states that increased rural interstate speed limits. Thus, these 21 states along with the seven that retained the $55 \mathrm{mph}$ limit form our 28 state sample. $^{9}$

Econometric Methods. The equation used to estimate how individuals trade off time spent traveling against the probability of a fatality is:

$$
\ln (\text { Hours of Travel })_{\mathrm{srt}}=\beta \ln (\mathrm{VMT})_{\mathrm{srt}}+\theta \ln (\text { Fatalities })_{\mathrm{srt}}+v_{\mathrm{srt}},
$$

where $v_{\mathrm{srt}}=\alpha_{\mathrm{sr}}+\eta_{\mathrm{rt}}+\mu_{\mathrm{st}}+v_{\mathrm{srt}}$. Here, s references state, $\mathrm{r}$ indicates roadtype, and $\mathrm{t}$ indexes year. The dependent variable is the natural logarithm of hours of travel (that is, the reciprocal of the average speed multiplied by VMT) and ln (VMT) srt, the natural logarithm of vehicle miles of travel, is a control. Thus

the parameter of interest, $\theta$, measures the elasticity of time spent traveling with respect to fatalities, holding constant VMT.

There are a number of potential sources of bias that we can control with state, year, and roadtype dummy variables and many of their interactions. Even with the inclusion of the multitude of fixed effects indicated in $v_{\text {srt, }}$ however, $\theta$ is not robust to time varying state-roadtype determinants of fatalities. As an example, it is possible that individuals drive more slowly when there is poor weather or heavy road repair precisely due to safety concerns. Our solution to this identification problem is to find a variable that affects speeds and that only affects fatalities through its effect on speeds. As Ashenfelter and Greenstone (2004) demonstrate, a plausible instrument is whether the $65 \mathrm{mph}$ speed limit was in force.

\section{Results}

Table 1 reports results from the estimation of equation (3). In column (1) the sample is limited to data from the rural interstate roads and the specification includes year-roadtype and state-roadtype fixed effects. In column (2) the sample is enlarged to include observations on urban interstates and rural arterials, allowing for the addition of state-year indicators to the specification. The first panel presents 
results from ordinary least squares (OLS) estimation, while the second panel uses an indicator for whether the 65 mph speed limit was in force as an instrumental variable as outlined in the previous section. For each regression, the table reports the parameter estimate on the fatalities variable and the heteroskedastic consistent standard error in parentheses. The implied estimate of $\mathrm{V}$, the monetary value of the time saved per marginal fatality, is calculated by multiplying the elasticity by the ratio of hours traveled to total fatalities on rural interstates in adopting states from 1982-86 (6.122 billion/5,187) and by the 1986 average wage rate in adopting states (\$12.33 in 1997\$) and is presented in brackets.

The OLS regressions indicate that speeds and fatalities are virtually uncorrelated. Although this may seems puzzling at first, it is not very surprising. After all, people will choose to travel more slowly in order to reduce the likelihood of a fatality when a road is unsafe (e.g., due to poor weather).

The IV estimates paint a very different picture. In particular, the two estimates of $\theta_{\text {IV }}$ indicate that a $10 \%$ increase in fatalities is associated with a $1 \%$ to $1.1 \%$ reduction in travel times and these estimates would be judged statistically significant by conventional criteria. The similarity between the results in columns (1) and (2) indicates that in this setting state-year unobservables are not an important source of bias. The associated estimate of the IV monetary value of time saved per marginal fatality is approximately \$1.5 million (1997\$).

Overall, Table 1 has two primary findings. First, the OLS results illustrate the difficulty of making causal inferences when there is no exogenous variability in the data. In particular, the results in the top panel are consistent with the possibility that OLS will produce estimates of $\theta$ that are biased upwards due to individuals' compensatory behavior. Second, the use of the introduction of the 65-mph speed limit as an instrumental variable appears to mitigate this bias, if not entirely remove it.

We now undertake separate analyses for each of the 21 adopting states. Table 2 presents stateby-state estimates and standard errors of the IV elasticity between time saved and fatalities (cols. (1) and (2)) and the monetary value of time saved per marginal fatality (col. (3)). These are obtained from fitting versions of equation (3) that include the logarithm of VMT interacted with roadtype and state-roadtype, roadtype-year, and state-year fixed effects as controls. The sample for each of these regressions includes 
observations on rural interstates, urban interstates, and rural arterials from the 7 states that retained the 55 mph limit and the state for which the estimate applies.

The entries reveal that 19 of the 21 IV elasticities have the expected negative sign. Notably, only 3 (Colorado, Iowa, and South Dakota) of the elasticities would be judged statistically significant at conventional levels. The estimated value of time saved per marginal fatality ranges from $-\$ 1.12$ million (Arkansas) to $\$ 9.71$ million (Wisconsin). As we report below, however, this enormous variability is entirely consistent with sampling error in the estimates.

Figure 1 provides an opportunity to assess the extent of the variability in the estimates in the context of their precision. It plots the state-specific estimated values of time saved per fatality on the yaxis against the t-statistics of the IV elasticities on the x-axis. Each state is denoted with its two letter abbreviation. The letters "s" and " $\mathrm{f}$ " in parentheses indicate that the reduced form relationships between the instrument and hours spent traveling (i.e., the inverse of speed) and fatalities, conditional on the same set of covariates as the Table 2 specification, is statistically significant at the $5 \%$ level, respectively. It is evident that the extreme estimates, both negative and positive, are the ones where the elasticity is estimated with the least precision. For example, all of the estimates with associated t-statistics greater than 1.4 are in the relatively narrow range of $\$ 1.2$ million to $\$ 3.2$ million. To more systematically assess the variability of these estimates, we implemented an F-test of the hypothesis that the 21 elasticities are equal and failed to reject the null (p-value $=0.24)$.

To explore what might happen if each state in our data were studied separately, with publication of each study determined by the standard peer-review process, we provide the analysis in Table 3. Here, we consider each state-specific estimate of $\mathrm{V}$ a separate study that could have been undertaken by a researcher, submitted to a journal, and considered for publication by reviewers and the editor. ${ }^{10}$ We further assume that the 21 adopting states with complete data form the universe of states that raised the speed limit. The different panels report the weighted mean and standard error (in parentheses) of the $\mathrm{V}_{\mathrm{i}}$ 's from alternative "publication rules," where the weight is the inverse of the IV elasticity’s standard error. Each of these rules leads to an estimate of $V$ that is based on a different subsample of the universe of $V_{i}$ 's. 
The first panel reveals that the weighted average of all 21 state-specific estimates of $\mathrm{V}$ is $\$ 1.14$ million. This estimate serves as the basis of comparison for the alternative publication rules. In the second panel, we impose the rule that to be published a study must have an IV elasticity with an associated p-value $<.05$. This is believed to be a common basis for determining a study's value. Three of the estimates meet this criteria and their weighted average is $\$ 2.31$. Thus, this publication rule produces an estimate of $\mathrm{V}$ that is more than twice as large as the one based on the universe of estimates. This is especially notable in a setting where the hypothesis that the treatment effect is homogeneous cannot be rejected. The third and fourth panels impose publication rules that require p-values $<.05$ for the reduced form relationships between the instrument and fatalities and speed, respectively. They also produce upward biased estimates of $\mathrm{V}$, although the bias is smaller.

\section{Conclusions}

This study has demonstrated that omitted variables and publication bias can lead to severely biased estimates of the monetary value of time saved per marginal fatality. As a result, estimates of the value of a statistical life that do not account for these factors will also be severely biased. Although our empirical results are obtained in the context of a study of choices about road safety, we suspect that the same issues plague the estimation of the value of a statistical life in other contexts. 


\section{REFERENCES}

Ashenfelter, Orley; Harmon, Colm and Oosterbeek, Hessel. "A Review of Estimates of the Schooling/Earnings Relationship, with Tests for Publication Bias.” Labour Econmics, 1999,_6(4), pp. 453-70.

Ashenfelter, Orley and Greenstone, Michael. "Using Mandated Speed Limits to Measure the Value of a Statistical Life.” Journal of Political Economy, 2004, forthcoming.

Black, Dan A. and Kneisner, Thomas J. “On the Measurement of Job Risk in Hedonic Wage Models.” Journal of Risk and Uncertainty, December 2003, 27(3), pp. 205-20.

Blomquist, Glenn C. "Self Protection and Averting Behavior, Values of Statistical Lives, and Benefit Cost Analysis of Environmental Policy.” Mimeo, University of Kentucky, 2001.

Greenstone, Michael. “A Reexamination of the Systemwide Effects of the 65 Mph Speed Limit." Economic Inquiry, 2002, 40(2), pp. 271-8.

Hedges, Larry V. “Modeling Publication Selection Effects in Meta-Analysis.” Statistical Science, 1992, 7(2), pp. 246-55.

Khan, Nisar; Kumares C. Sinha, and McCarthy, Patrick S. An Analysis of Speed Limit Policies for Indiana. West Lafayette, IN: Joint Transportation Research Project, Purdue University, 2000.

National Research Council (U.S.) Transportation Research Board. Fifty-five, a Decade of Experience. Washington, DC: National Academy Press, 1984.

Viscusi, W. Kip. “The Value of Risks to Life and Health.” Journal of Economic Literature, 1993, 31, pp. 1912-46.

Thaler, Richard and Rosen, Sherwin. “The Value of Saving a Life: Evidence from the Labor Market,” in Nestor E. Terlecky, ed., Household Production and Consumption. Cambridge, MA: NBER, 1976, pp. 265-98.

U.S. Department of Transportation. Effects of the 65 MPH Speed Limit through 1990: A Report to Congress. Washington, DC: National Highway Traffic Safety Administration, 1992. 
Table 1: Estimates of the Monetary Value of Time Saved per Marginal Fatality

\begin{tabular}{|c|c|c|}
\hline Sample & $\begin{array}{c}\text { Rural Interstates } \\
\text { (1) }\end{array}$ & $\begin{array}{c}\text { Rural Interstates, } \\
\text { Urban Interstates, \& } \\
\text { Rural Arterials } \\
\text { (2) }\end{array}$ \\
\hline Prdinary Least Squares & $\begin{array}{c}-.003 \\
(.007) \\
{[\$ 0.04 \text { million }]}\end{array}$ & $\begin{array}{c}.001 \\
(.003) \\
{[-\$ 0.01 \text { million }]}\end{array}$ \\
\hline Instrumental Variables & $\begin{array}{c}-.113^{* *} \\
(.034) \\
{[\$ 1.64 \text { million] }}\end{array}$ & $\begin{array}{c}-.099 * * \\
(.034) \\
{[\$ 1.44 \text { million] }}\end{array}$ \\
\hline $\begin{array}{l}\text { Year-Roadtype Indicators } \\
\text { State-Roadtype Indicators } \\
\text { State-Year Indicators }\end{array}$ & $\begin{array}{l}\text { Yes } \\
\text { Yes } \\
\text { No }\end{array}$ & $\begin{array}{l}\text { Yes } \\
\text { Yes } \\
\text { Yes }\end{array}$ \\
\hline
\end{tabular}

Notes: Each set of entries reports the parameter on ln (Fatalities), its heteroskedasticconsistent standard error (in parentheses), and the associated monetary value of time saved per marginal fatality (in square brackets) from the fitting of different versions of equation (3). In column (1) the sample includes observations on rural interstates from the 28 states with complete data. In column (2) observations on urban interstates and rural arterials are added to the column (1) sample. In each specification, ln (vehicle miles of travel) interacted with road type is included as a control. The other controls are listed at the bottom of the table. In the top panel, equation (3) is fit by ordinary least squares while in the second panel an indicator for whether the $65 \mathrm{mph}$ speed limit was in force is an instrumental variable for ln (Fatalities). See the text and Ashenfelter and Greenstone (2004) for further estimation details. * indicates significance at 5\% level and ** indicates significance at $1 \%$ level. 
Table 2: State by State Estimates of Monetary Value of Time Saved per Marginal Fatality

\begin{tabular}{lccc}
\hline \hline & \multicolumn{2}{c}{ IV Elasticity } & \multicolumn{2}{c}{ Estimated Value of } \\
& $\begin{array}{c}\text { Parameter } \\
\text { Estimate } \\
(1)\end{array}$ & $\begin{array}{c}\text { Standard } \\
\text { Error } \\
(2)\end{array}$ & $\begin{array}{c}\text { Time Saved per Fatality } \\
\text { Millions of 1997 \$s }\end{array}$ \\
\hline \hline Arizona & -0.239 & $(.215)$ & $\$ 3)$ \\
Arkansas & 0.094 & $(.072)$ & $-\$ 1.92$ \\
California & -0.431 & $(.403)$ & $\$ 4.75$ \\
Colorado & $-0.212^{*}$ & $(.089)$ & $\$ 2.31$ \\
Idaho & -0.241 & $(.201)$ & $\$ 2.05$ \\
Illinois & -0.128 & $(.076)$ & $\$ 3.19$ \\
Indiana & -0.045 & $(.497)$ & $\$ 0.70$ \\
Iowa & $-0.106^{*}$ & $(.053)$ & $\$ 2.97$ \\
Kansas & -0.113 & $(.077)$ & $\$ 1.96$ \\
Kentucky & -0.071 & $(.049)$ & $\$ 1.24$ \\
Michigan & -0.033 & $(.029)$ & $\$ 0.99$ \\
Mississippi & -0.079 & $(.120)$ & $\$ 0.76$ \\
Nevada & -0.082 & $(.098)$ & $\$ 0.49$ \\
North Carolina & -0.061 & $(.035)$ & $\$ 1.09$ \\
Ohio & 0.013 & $(.027)$ & $-\$ 0.47$ \\
Oregon & -0.340 & $(.536)$ & $\$ 5.41$ \\
South Carolina & -0.099 & $(.077)$ & $\$ 1.68$ \\
South Dakota & $-0.110^{*}$ & $(.049)$ & $\$ 1.92$ \\
Tennessee & -0.020 & $(.043)$ & $\$ 0.29$ \\
Wisconsin & -0.330 & $(.609)$ & $\$ 9.71$ \\
Wyoming & -0.055 & $(.088)$ & $\$ 0.50$ \\
\hline \hline Not & & & \\
\hline
\end{tabular}

Notes: For each row the entries report the results from separate regressions where the sample includes observations on rural interstates, urban interstates, and rural arterials from the 7 states that retained the 55 mph limit and the state for which the estimate applies. The specifications regress ln (Hours of Travel) on ln (Fatalities), and the controls are ln (vehicle miles of travel) interacted with roadtype and state-roadtype, roadtype-year, and state-year fixed effects. An indicator for whether the $65 \mathrm{mph}$ speed limit was in force is an instrumental variable for $\ln$ (Fatalities). Columns (1) and (2) report the parameter on ln (Fatalities) and its heteroskedastic-consistent standard error (in parentheses). Column (3) reports the estimated value of time saved per marginal fatality, which is calculated by multiplying the IV elasticity (column (1)) by the state-specific ratio of hours traveled to total fatalities and the state-specific mean hourly wage. See the text and Ashenfelter and Greenstone (2004) for further estimation details. * indicates significance at $5 \%$ level and ** indicates significance at $1 \%$ level 
Table 3: Estimates of Monetary Value of Time Saved (1997\$) per Marginal Fatality Based on State by State Estimates and Alternative Publication Rules

\begin{tabular}{|c|c|}
\hline Sample & $(1)$ \\
\hline All States & $\begin{array}{c}\$ 1.14^{* *} \\
(\$ 0.28)\end{array}$ \\
\hline $\mathrm{N}$ & 21 \\
\hline States with Significant IV Elasticity & $\begin{array}{c}\$ 2.31^{* *} \\
(\$ 0.29)\end{array}$ \\
\hline $\mathrm{N}$ & 3 \\
\hline States with Significant Fatality Effect & $\begin{array}{c}\$ 1.27 * * \\
(\$ 0.36)\end{array}$ \\
\hline $\mathrm{N}$ & 9 \\
\hline States with Significant Speed Effect & $\begin{array}{c}\$ 1.48 * * \\
(\$ 0.38)\end{array}$ \\
\hline $\mathrm{N}$ & 13 \\
\hline \multicolumn{2}{|c|}{$\begin{array}{l}\text { Notes: Each panels report the weighted mean and standard error (in } \\
\text { parentheses) of the } V_{\mathrm{i}} \text { 's from alternative "publication rules," where } \\
\text { the weight is the inverse of the IV elasticity's standard error from } \\
\text { Table } 2 \text {. See the text for further details. * indicates significance at } \\
5 \% \text { level and } * * \text { indicates significance at } 1 \% \text { level }\end{array}$} \\
\hline
\end{tabular}


Figure 1: Estimated Value of Time Saved per Marginal Fatality by t-Statistic of IV Elasticity

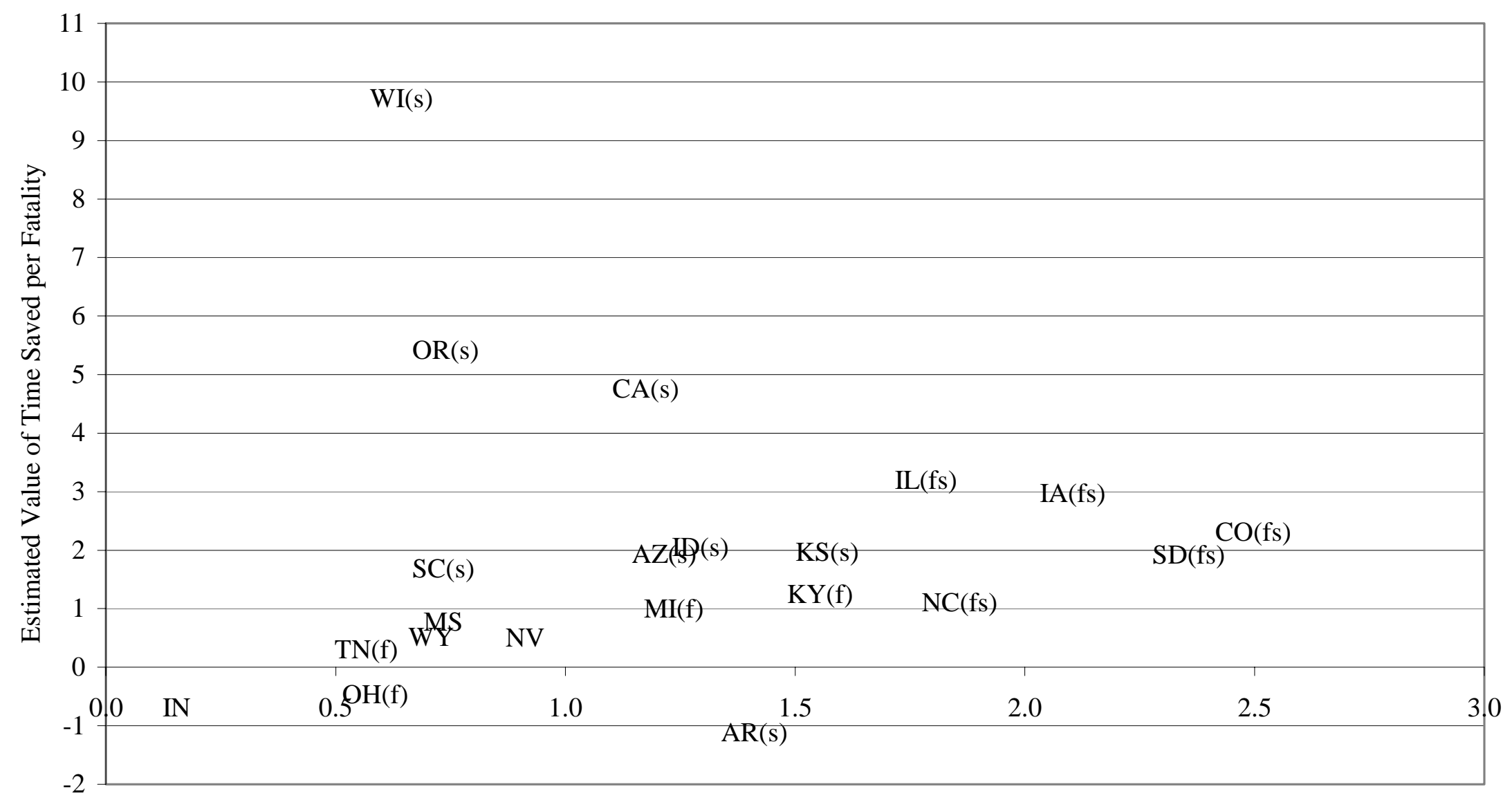

t-Statistic of IV Elasticity 
* Industrial Relations Section, Princeton University, Firestone Library, Princeton, NJ 08544 and NBER (e-mail: c6789@princeton.edu) and MIT Department of Economics, 50 Memorial Drive, E52-391B, Cambridge, MA 02142, and American Bar Foundation and NBER (e-mail: mgreenst@mit.edu), respectively.

${ }^{1}$ This paper is an extension of Ashenfelter and Greenstone (2004), which explains a number of related issues in greater detail.

${ }^{2}$ For useful, detailed surveys see Viscusi (1993) and Blomquist (2001).

${ }^{3}$ See especially Black and Kniesner (2003).

${ }^{4}$ There are easily implemented econometric methods for use with meta-analyses of multiple studies of the VSL to test and correct for publication bias problems. See Hedges (1992) and Ashenfelter, Harmon and Oosterbeek (1999).

${ }^{5}$ See especially Thaler and Rosen (1976).

${ }^{6}$ In this special case, $\mathrm{E}\left(\mathrm{V}_{\mathrm{i}} \mid\right.$ Adoption $)$ is greater than $\mathrm{V}^{*}$, the value of a statistical life that is common among both adopters and non-adopters.

${ }^{7}$ Both rural and urban interstate roads have multiple lanes, with traffic separated by direction and controlled access. Rural arterials generally have one lane in each direction, but they have wide lanes and shoulder lanes. Access to them is less controlled than to interstates, but more than to any other type of road. See National Research Council (1984).

${ }^{8}$ Highway Statistics, Table VM-2, Federal Highway Administration, various issues.

${ }^{9}$ See Greenstone (2002) and Ashenfelter and Greenstone (2004) for further details on the data and summary statistics.

${ }^{10}$ In fact, there are numerous state-specific studies of the consequences of altered speed limits. See NRC (1984) and U.S. Department of Transportation (1992). 